\title{
高等教育としての日本語 \\ 一HKQF の視点からー \\ Japanese as a subject of higher education in Hong Kong
}

\section{小玉博昭 \\ 香港大学博士課程}

\section{要旨}

香港では多くの機関で日本語プログラムが開講されおり、それは高等教育でも 同じ状況である。また同じ高等教育であっても、学位以外の資格を授与寸る機関 やプログラムもあり、個々のプログラムや機関で扱われる日本語の教育内容や 位置づけの違いを見つけるのが困難な状況になっていることは否めない。この ような状況で高等教育における日本語を明確に差別化する助けとなる枠組みが 香港政府によって導入された。教室の中からだけでは捉えにくい香港全体の日本 語の位置づけを、Hong Kong Qualification Framework (HKQF)とその一端である QF Level という概念から調査し、分類した。この調査から、QF Level 5 以上の レベルからはほぼ大学が開講する学位プログラムによって占められており、学位 以外の資格が得られるプログラムはほとんど見られないことがわかった。高等 教育とほかの教育とを差別化するという意味での HKQF には一定の評価が期待 できるが、香港の高等教育の核心部分である理論的枠組みには批判もあり、個々 の教師がそれらの諸問題や枠組みについて理解しておく必要性について論じた。

キーワード

香港、高等教育、HKQF、QF Level、Outcome-Based Teaching and Learning 


\section{小玉博昭 香港大学博士課程}

\section{1.はじめに}

香港において日本語は大変人気のある言語の一つであるため、多くの機関で 日本語プログラムやコースが開講されている。また、2011 年からは香港の大学 入試のための統一試験である Hong Kong Diploma of Secondary Education (HKDSE) の科目に日本語 ${ }^{1}$ が追加され、香港における日本語学習が益々注目されるように なった。国際交流基金(2017) $)^{2}$ の調査による香港の日本語学習者の内訳は次の通り である。

表 1 : 学習者数内訳 国際交流基金(2017)より抜粋

\begin{tabular}{|c|c|c|}
\hline 教育段階 & 学習者数 & 割合 \\
\hline 初等教育 & 1,143 & $5.1 \%$ \\
\hline 中等教育 & 1,663 & $7.4 \%$ \\
\hline 高等教育 & 3,636 & $16.1 \%$ \\
\hline その他 教育機関 & 16,171 & $71.5 \%$ \\
\hline 合計 & 22,613 & $100.0 \%$ \\
\hline
\end{tabular}

香港における日本語学習の特徵として、正規の教育機関（初等・中等・高等 教育機関）が三割以下と低く、民間の語学学校や一般向けの大学付属機関が設置 するプログラム・コース、独学などでの学習が大部分を占めるという点が挙げ られる。このように香港では多くの教育機関で日本語学習が可能となっている ため、多種にわたる教育機関での日本語の教育内容を差別化する必要が出てくる。 仮に差別化がされていないとすれば、初等教育で提供されている教育内容と高等 教育で提供されている教育内容が重複することとなり、高等教育の在り方に疑問 が生じる恐れがあろう。本稿では香港で提供されている高等教育における日本語 プログラム・コースが、どのようにその他の教育と差別化されているかについて、 香港で採用されている枠組みを参照しながら論じていく。

\footnotetext{
${ }^{1}$ HKDSE の日本語科目はケンブリッジ大学の一機関である Cambridge Assessment International Education が問題作成及び評価をつけることになっている。

${ }^{2}$ http://www.jpf.go.jp/j/project/japanese/survey/area/country/2016/hongkong.html
} 


\section{2. 香港における学位と資格に関わる枠組み}

\section{1 Hong Kong Qualification Framework}

香港では学位を含めた資格を授与するプログラムは全て Hong Kong Qualification Framework (HKQF) $)^{3}$ という資格に関する枠組みで扱われている。 HKQF は 2008 年に香港政府の機関である教育局が実施した枠組み (Education Bureau, 2012) で、学位授与をする大学だけでなく、民間の教育機関で開講されて いる専門的な知識や技術についての資格を与えるプログラム・コースもこの枠 組みで管理されている。香港の高等教育における日本語を捉える上で、重要だと 考えられるのは HKQF 内の次の二点である。

1. Qualification Framework Level (QF Level $)^{4}$

2. Award Titles Scheme (ATS) ${ }^{5}$

QF Level では学位・資格を 7 段階のレベルに分類しており、最高レベルは博士 (Doctor)の学位で、QF Level 7 と設定されている。ATS は学士(Bachelor)や修士 (Master)などの学位のほかに証書(Certificate)や文憑(Diploma)などの学位以外の 資格について QF Level や単位数等を踏まえながら、各学位・資格の概要を記した ものである。表 2 は香港における学位・資格の一覧とそれに対応する QF Level を表している。

\section{表 2：QF Level と学位・資格一覧 Education Bureau (2017)より抜粋}

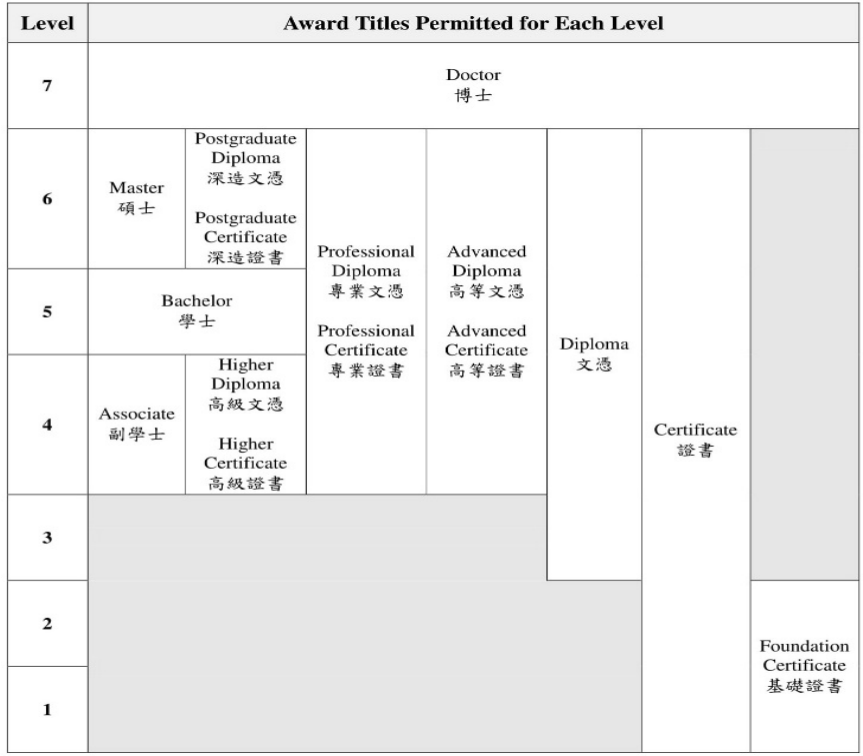

QF Level 及びATS、それぞれの詳細については次の節で述べていく。

\footnotetext{
${ }^{3}$ https://www.hkqf.gov.hk/en/home/index.html

${ }^{4}$ https://www.hkqf.gov.hk/en/KeyFeatures/levels/index.html

${ }^{5}$ https://www.hkqf.gov.hk/en/KeyFeatures/ats/index.html
} 


\subsubsection{Qualification Framework Level (QF Level)}

QF Level は QF Level 1 から 7 までのレベルを示し、それぞれのレベルの教育 内容が Generic Level Descriptors (GLD)に記載されている。GLDには 7 段階全ての レベルについて記載されており、Knowledge \& Intellectual Skills (知識及び知的 スキル), Processes (プロセス), Application, Autonomy \& Accountability (応用・自律 及び管理能力), Communication, IT and Numeracy (コミュニケーション・IT 及び 数理能力) の四つのカテゴリーに分けられた記述がある。表 3 は例として QF Level 5 の学士レベルに相当する GLD を挙げたものである。

\section{表 3：QF Level 5 の GLD Education Bureau (2017)より抜粋}

\begin{tabular}{|c|c|c|c|c|}
\hline \multirow[t]{2}{*}{ Level } & \multicolumn{4}{|c|}{ Generic Level Descriptors } \\
\hline & Knowledge \& Intellectual Skills & Processes & $\begin{array}{l}\text { Application, Autonomy \& } \\
\text { Accountability }\end{array}$ & Communication, IT and Numeracy \\
\hline 5 & $\begin{array}{l}\text { - Generate ideas through the } \\
\text { analysis of abstract information } \\
\text { and concepts } \\
\text { - Command wide ranging, } \\
\text { specialised technical, creative } \\
\text { and/or conceptual skills } \\
\text { - Identify and analyse both } \\
\text { routine and abstract professional } \\
\text { problems and issues, and } \\
\text { formulate evidence-based } \\
\text { responses } \\
\text { - Analyse, reformat and evaluate } \\
\text { a wide range of information } \\
\text { - Critically analyse, evaluate } \\
\text { and/or synthesise ideas, } \\
\text { concepts, information and } \\
\text { issues } \\
\text { - Draw on a range of sources in } \\
\text { making judgments. }\end{array}$ & $\begin{array}{l}\text { - Utilise diagnostic and creative } \\
\text { skills in a range of technical, } \\
\text { professional or management } \\
\text { functions } \\
\text { - Exercise appropriate } \\
\text { judgement in planning, } \\
\text { design, technical and/or } \\
\text { supervisory functions related } \\
\text { to products, services, } \\
\text { operations or processes. }\end{array}$ & $\begin{array}{l}\text { - Perform tasks involving } \\
\text { planning, design, and } \\
\text { technical skills, and involving } \\
\text { some management functions } \\
\text { - Accept responsibility and } \\
\text { accountability within broad } \\
\text { parameters for determining } \\
\text { and achieving personal and/or } \\
\text { group outcomes } \\
\text { - Work under the mentoring of } \\
\text { senior qualified practitioners } \\
\text { - Deal with ethical issues, } \\
\text { seeking guidance of others } \\
\text { where appropriate. }\end{array}$ & $\begin{array}{l}\text { - Use a range of routine skills and } \\
\text { some advanced and specialized } \\
\text { skills in support of established } \\
\text { practices in a subject/discipline, } \\
\text { for example: } \\
\text { - Make formal and informal } \\
\text { presentations on } \\
\text { standard/mainstream topics in the } \\
\text { subject/discipline to a range of } \\
\text { audiences } \\
\text { - Participate in group discussions } \\
\text { about complex subjects; create } \\
\text { opportunities for others to } \\
\text { contribute } \\
\text { - Use a range of IT applications to } \\
\text { support and enhance work } \\
\text { - Interpret, use and evaluate } \\
\text { numerical and graphical data to } \\
\text { achieve goals/targets. }\end{array}$ \\
\hline
\end{tabular}

このように学士相当のレベルの学位や資格を授与するプログラムでは、QF Level 5 の GLD に当てはまる教育内容でなければならないことになる。大学が 授与寸る学位である学士でなくても、証書や文憑でも QF Level 5 か、それ以上の 資格を得られるプログラムもあるが、QF Level が高くなる程、受講資格も高度な ものを求められるようになる。更に、開講する機関側にも各 QF Level に応じた 数々の基準が求められ、その基準が満たせなければ、そのプログラムを開講でき ない仕組みになっている。これは Qualification Assurance (QA) ${ }^{6}$ と呼ばれる異なる 枠組みで管理されており、ある周期で QA Audit という教育内容をチェック寸る

${ }^{6}$ https://www.hkqf.gov.hk/en/qa/index.html

研究ノート 
監査が入り、QF Level に準じた教育内容の提供を維持する機能をもっている。QA に関連する枠組みについては本稿では触れないこととする。

\section{1.2 Award Titles Schemes (ATS)}

ATS は香港政府が 2008 年に実施した HKQS に基づき、2013 年に導入された ものである。それまで数多くあった資格のタイトルをまとめ、標準化したことが その大きな特徵の一つである。また、学習者が資格の取得を検討する際、各教育 機関が公開する情報を元にその資格が取得できるプログラムを探すことになるが、 その表記の方法等も一本化されていなかった。ATSの導入より、受講後に得られる 資格がどのレベルの内容に相当するのかが明確となった。

例）

1. Certificate Programme in Japanese-Chinese Translation (QF Level 4)

2. Japanese-Chinese Translation

上記の二つの日本語関連のプログラムとコースはそれぞれ香港で一般向けに 開講されている日中翻訳の証書プログラムと、大学の学部生を対象にした同じく 日中翻訳のコースである。1.のプログラムが Certificate (証書)であること、そして QF Level 4 であることから、学士(QF Level 5)取得を目的とした学部生対象の コースの内容と差別化されていることがわかる。このように、扱うトピックが 同じプログラムやコースであっても、QF Level が提示されることによって、 学習者が受講後に得られる資格のレベルを考慮に入れた上で、受講する機関や プログラム・コースを選択することができるようになった。概して初級日本語の 証書プログラムは QF Level 2 から 3 であることが多く、プログラム修了後には Certificate in Basic Japanese (初級日本語証書)が授与される。取得した証書は日本 語の語学力や学習歴を証明するものとして、履歴書に添付することができる。

\section{2 Outcome-Based Teaching and Learning (OBTL)}

香港における教育の核心部分に Outcome-Based Teaching and Learning (OBTL) ${ }^{7}$ の 概念が導入されている。OBTL は OBE (Outcome-Based Education)とも呼ばれ、

「教師が何を教えるか」という視点から作られた教師中心(Teacher-Centred)の カリキュラムではなく、学習を通し、最終的に「学習者がどのようなことができる ようになるのか」(Learning Outcomes)に重点を置いた学習者中心(Student-Centred) の考え方であるとされる(Spady, 1994; Schwarts \& Cavener, 1994; Faouzi et al, 2003)。

7 香港のほかにはアメリカ、オーストラリア、ヨーロッパ連合でこのような結果・成果重視の 枠組みが教育に組み込まれている。(Kennedy, 2011) 
そのため OBTL を軸にカリキュラムを構築する場合は、学習者がプログラム修了 時までに得られるであろう学習成果や結果(Intended-Learning Outcomes, ILOs) から逆算して、教育内容を設計していくことになる。これは、これまでの教師 中心の教師が教える内容から積み上げて授業内容を作っていく作業とは正反対の ものである。OBTL では学生のパフォーマンスをILOs が達成できた否かで評価を するため、ILOs に記述される項目は全て測定可能なものでなければならない という原則がある。そのため、ILOs を記述する際には、Action Verbs ${ }^{8}$ と言われる 実際的な行動を表す動詞を選び、think や feel など客観的に評価のできない動詞が 避けられる。事実、表 3 にある GLD は全て Action Verbs で記述がされており、 学習者の心理的状態や感覚を表す表現は使われていない。

OBTL は 2005 年に University Grants Committee (UGC) ${ }^{9}$ という香港の高等教育の 発展や補助金についての審議を行う機関が、UGC から補助金を得ている大学 ${ }^{10} へ$ 本格的に導入したものである。OBTL が導入された背景には経済協力開発機構 (OECD)が掲げる教育観 ${ }^{11}$ があると言われている。(Kennedy, 2015)

\section{3. 調查}

\section{1 調查の概要}

香港で開講されている学位を含めた資格を授与寸るプログラム及びその教育 機関数を調查し、QF Level 別に整理した。このデータから、香港の高等教育機関 で開講されている日本語関連プログラムとその他の教育機関でのプログラムとが どのように住み分けされているのか、QF Level の視点から明らかにすることを この調查の目的とする。

表 4 : 調査の詳細

\begin{tabular}{|c|c|}
\hline 対象 & 香港における日本語関連の学位・資格を授与するプログラム \\
\hline 調査方法 & 香港教育局のQualifications Register (QR)サーチエンジン \\
\hline 検索ワード & \multicolumn{2}{c}{ Japanese } \\
\hline
\end{tabular}

8 香港城市大学が構築した ILOs の記述に使われる Action Verbs を体系化し、段階ごとに整理 されたものが有効活用されている。

http://www.cityu.edu.hk/edge/obtl/obtl_student/av/obtlactionverbs.htm

9 http://www.ugc.edu.hk/eng/ugc/index.html

10 UGC から補助金を受けている大学は UGC-funded Universities と呼ばれ、香港大学、香港 中文大学を含む計 8 校の公立大学が含まれている。

11 “institutions want to be recognized as providers of good quality higher education. They understand that competing on the basis of research only is not sufficient to ensure the reputation of the university. As such, they want to find new ways of demonstrating performance. They respond to students' demand for valuable teaching: students want to ensure that their education will lead to jobs and will give them the skills needed in the society of today and tomorrow. (Henard. 2010, p.6)” 
表 4 が示すように、日本語関連のプログラムを検索したため、検索ワードを 「Japanese」とした。そのため、日本語関連のプログラムであったとしても、 プログラムのタイトルやその概要欄に「Japanese」の記述がないものは本稿の 調査結果には含まれていないことになる。また、日本語には関連がないと考え られるもの（日本食の調理法や美容についてのプログラム等）は調査結果から 外してある。更に本稿の目的は高等教育における日本語とそのほかの教育との 差別化に焦点をあてているため、QF Level 4（日本の短大相当）以上のプログラム に限定した。そのため、QF Level 3 以下のプログラムは調査の対象にはして いない。

\section{2 調査の結果}

表 5 は香港政府が公開している QR の検索エンジンに、検索ワード「Japanese」を 入力して検索をしたものである。

表 5 ：調査結果

\begin{tabular}{|l|c|l|}
\hline \multicolumn{1}{|c|}{ 学位・資格名 } & QF Level & \multicolumn{1}{|c|}{ 機関名 } \\
\hline $\begin{array}{l}\text { Higher Diploma in Language and } \\
\text { Corporate Communication (Japanese) }\end{array}$ & 4 & 香港専業進修学校 \\
\hline $\begin{array}{l}\text { Advanced Diploma in Japanese } \\
\text { Communication and Culture }\end{array}$ & 4 & 香港大学専業進修学院 \\
\hline $\begin{array}{l}\text { Higher Diploma in Applied Japanese } \\
\text { Language }\end{array}$ & 4 & 香港中文大学専業進修学院 \\
\hline $\begin{array}{l}\text { Diploma in Japanese Communication and } \\
\text { Culture }\end{array}$ & 4 & 香港大学専業進修学院 \\
\hline $\begin{array}{l}\text { Higher Diploma in Trilingual Studies for } \\
\text { Business Communication }\end{array}$ & 4 & 香港中文大学専業進修学院 \\
\hline $\begin{array}{l}\text { Certificate in Japanese Communication } \\
\text { and Culture }\end{array}$ & 4 & 香港大学専業進修学院 \\
\hline Diploma in Applied Japanese & 4 & 香港公開大学李嘉誠専業進修学院 \\
\hline Associate of Arts in Japanese Studies & 4 & UOW College Hong Kong \\
\hline Associate of Arts in Japanese Studies & 4 & 香港城市大学専上学院 \\
\hline Higher Diploma in Japanese Studies & 4 & 香港公開大学李嘉誠専業進修学院 \\
\hline Advanced Diploma in Japanese & 4 & 香港大学専業進修学院 \\
\hline $\begin{array}{l}\text { Advanced Certificate in Japanese } \\
\text { Communication and Culture }\end{array}$ & 4 & 香港大学専業進修学院 \\
\hline $\begin{array}{l}\text { Higher Diploma in Japanese Language and } \\
\text { Communications }\end{array}$ & 続進修学院 \\
\hline
\end{tabular}




\begin{tabular}{|l|c|l|}
\hline \multicolumn{1}{|c|}{ 学位・資格名 } & QF Level & \multicolumn{1}{|c|}{ 機関名 } \\
\hline Bachelor of Arts & 5 & 香港中文大学 \\
\hline $\begin{array}{l}\text { BA (Hons) International Business } \\
\text { Communication with Japanese }\end{array}$ & 5 & 香港城市大学専業進修学院 \\
\hline $\begin{array}{l}\text { Postgraduate Diploma in Teaching } \\
\text { Japanese as a Foreign Language }\end{array}$ & 6 & 香港大学専業進修学院 \\
\hline $\begin{array}{l}\text { Master of Arts in Japanese Studies for the } \\
\text { Professions }\end{array}$ & 6 & 香港理工大学 \\
\hline $\begin{array}{l}\text { Master of Arts in Japanese Media and } \\
\text { Communication }\end{array}$ & 6 & 香港理工大学 \\
\hline Master of Philosophy & 6 & 香港大学 \\
\hline Master of Philosophy & 6 & 香港中文大学 \\
\hline Master of Arts & 6 & 香港中文大学 \\
\hline Doctor of Philosophy & 7 & 香港大学 \\
\hline Doctor of Philosophy & 7 & 香港中文大学 \\
\hline
\end{tabular}

表 5 には合計 23 の学位・資格とそれを授与する教育機関が QF Level の順に 並べられている。専業進修学院や持続進修学院はそのほとんどが大学の付属機関 で一般向けのプログラムやコースの開講、短大相当の二年制全日プログラムの Associate Degree (副学士) ${ }^{12}$ 、Higher Diploma(高級文憑)課程の設置を行っている 高等教育機関である。

日本語関連で学位（副学士、高級文憑、学士、修士、博士）以外の資格は Postgraduate Diploma in Teaching Japanese as a Foreign Language が最高位で、QF Level 6 となっている。表 2 を参照すると Postgraduate Diploma は Master (修士)と 同じレベルであることがわかる。また、高等教育機関が授与する学位と同程度だ ということを表す QF Level 4 以上のプログラムであっても、大学とその他の機関 (専業進修学院) などでも住み分けができており、QF Level 5 以上からはほぼ 大学が独占して高レベルのプログラムを開講していることがわかる。表 2 にる ように、Certificate は QF Level 1 から 7 に対応可能な資格であり、民間の語学 学校でも QF Level 4 以上の日本語プログラムを開講することは手続き上可能で あるが、今回の調査結果の中には高等教育機関以外の機関は検出されなかった。 このことから、同じ日本語のプログラムであっても、QF Level に応じて差別化が

12 Associate Degree (AD)と Higher Diploma (HD)は履修す心゙き授業における専門科目の割合が 異なり、AD はより一般教養科目が多く、HD は専門科目が多くを占める。 
できており、プログラムを提供する機関も、同じように住み分けされていること がうかがえる。

\section{4. まとめと考察}

香港では学位を含めた資格が取得できるプログラムは HKQF の枠組みで管理 され、教育内容により QF Level によって 7 段階のレベルに分けられている。この レベル分けにより、同じタイトルのプログラムであっても、QF Level や資格の 種類により差別化がされており、学習者が資格取得を目標にプログラムを選ぶ 場合に大きな助けとなっている。日本語のプログラムに関して言えば、民間の 語学学校から大学に及ぶまで多くの教育機関が日本語関連のプログラムを提供 している。高等教育の専門科目として日本語を学ぶ意義の一つに、その高度な 内容や専門性が挙げられるが、これまでは実際に受講するまで、その教育内容の 程度がわからなかった。HKQF の明確な分類により、それが可視化された功績は 大きいのではないだろうか。

他方、日本の高等教育は文部科学省の管轄であるが、香港の制度とは大きく 異なっている。文部科学省(2017) ${ }^{13}$ には「高等教育段階の大学においては、それ ぞれの大学が、自ら掲げる教育理念・目的に基づき、自主的・自律的に編成する こととされています。」とあり大学の教育内容を政府が管理、保持するといった 介入を行わないことを表している。この方針の長所は、大学ごとに異なる特徴的 なカリキュラムが認められ、視野の広い教育が期待できることである。しかし ながらこの長所は同時に影を残すことになり、高等教育とは思えないような教育 を提供することも可能だということである。実際に少子化による受験生の減少 から定員割れを起こす大学も出てきており、大学の教育レベル低下が問題となって きている。日本のこのような部分だけを見ると、香港の HKQF は良く機能して おり、香港の高等教育の教育レベルを一定に保っているように思える。

管理や保持という意味で HKQF は効果的な枠組みであると考えられるが、問題 点も同時に内包している。それは HKQF の根幹を成す OBTL への批判である。 OBTL の特徽は、コースやプログラムの学習目標や期待される熟達度(ILOs)を Action Verbs と呼ばれる動詞を使って明確に記述されることである。評価はこの ILOsが達成されたか否かで決定されるため、その名の通り Outcome Based（結果 中心・重視）である。しかしながら、この特徴はすなわち、その結果に至るまで のプロセスに重きを置いていないことになる。さらに、明確に提示された目標が

13 http://www.mext.go.jp/a_menu/koutou/daigaku/04052801/001.htm 
OBTL で重要な位置づけにあるが、教室の外では常に目標が与えられるわけでは なく、むしろ学習者自身が自らの学習の目標設定・学習設計をしなければなら ない場面がでてくるはずである。このような学習者の自律的な学習を促進する ための教育を視野に入れた場合、OBTL の考え方が果たして効果的なのか疑問を 投げかける意見もある(McCarth，1993)。また、最大の問題点としては、明確に 記述された学習目標が逆に学習者の創造性や可能性の足かせとなり、記述された 学習目標以上の成長が望めなくなるという点である(McCarth, 1993; Glatthorm, 1993)。これは、無限の可能性を秘める、創造性豊かな個々の学習者の学習の到達 地点・ゴールを定めることは容易ではないという考え方に基づくものである (McCarth, 1993; Achary et al, 2003)。

前述のように香港では異なる教育レベル（初等・中等・高等教育及び非正規 教育）の教育機関で日本語が開講されている。このことは教える側が授業準備を 寸る段階で気に留めておかなければならない点であろう。それは、日本語の基礎 レベルのプログラムやコースは香港の初・中等教育でも提供されているが、初・ 中等教育で提供されている基礎レベルの日本語と高等教育における基礎レベルの 日本語と同じ内容であってはならないはずだからである。ここまで述べてきた HKQF や QF Level、OBTL といった概念は、どちらかというと現場の教員よりも、 プログラムの事務的なサポートをするアドミニストレーションに関わるものが 多いように思われがちだが、複数の教育機関で授業を担当する教員や、一段階下 の教育レベルから上がってきたばかりの学生を担当する教員は、自身が所属する 教育レベルと隣接するほかの教育レベルで提供されている日本語の教育内容に ついて熟知している必要があるのではないだろうか。また、特に高等教育として の日本語を担当する教員については、OBTLの光と影についてよく理解しておく 必要もあろう。

\section{5. 今後の課題}

本稿は香港の高等教育における日本語がほかの教育とどのように差別化されて いるのかについて、香港政府が一般に公開している情報を参照しながら概観した。 また、特に高等教育機関の代表的存在である大学の教育の枠組みとして導入された OBTL についても触れた。しかし、本稿で調査対象にしたものはすべてプログラム を中心としたもので、そのプログラムを構成する個々のコースについては詳しく 見ることができなかった。同じ QF Level のプログラムであっても、コースの内容 により、ILOs が異なってくるため、本稿のテーマである「差別化」をより浮き 彫りにするためには、プログラムレベルからさらに深いコースレベルで日本語の 教育内容を吟味する必要があるように思われる。また、高等教育に従事する日本 語の教員にも意識調査などすれば、さらに緻密な考察が加えられたはずである。 これら香港の高等教育における日本語のデータ収集を主な改善点とし、今後の 課題としたい。 


\section{参考文献}

国際交流基金(2017)「2016 年度日本語教育機関調査結果」

<http://www.jpf.go.jp/j/project/japanese/survey/area/country/2016/hongkong.html >

(2017 年 11 月 29 日)

文部科学省(2017)「大学における教育内容・方法の改善等について」

<http://www.hkqr.gov.hk/HKQRPRD/web/hkqr-en/>>(2017 年 11 月 29 日)

Acharya, C. (2003). Outcome-based Education (OBE): a New Paradigm for Learning. Triannual Newsletter of the Centre for Development of Teaching and Learning, 7(3).

Education Bureau the Government of the Hong Kong Special Administration Region (2017).Qualification Register < http://www.hkqr.gov.hk/HKQRPRD/web/hkqr-en/> (2017 年 11 月 29 日)

Faouzi, B., Lansari, A., Al-Rawi, A., Abonamah, A. (2003). a Novel Outcome-based Education Model and its Effect on Student Learning, Curriculum Development, and Assessment. Journal of Information Technology Education, 2, 203-214.

Glatthorm, A. (1993). Outcome Based Education:Reform and the Curriculum Process. Journal of Curriculum and Supervision, 8, 324-363.

Henard, F. (2010). Learning our Lesson: Review of Quality Teaching in Higher Education. Paris: Organisation for Economic Cooperation and Development.

Kennedy, J.K. (2011). Conceptualising quality improvement in Higher Education: Policy, Theory and Practice for Outcome Based Learning in Hong Kong. Journal of Higher Education and Policy and Management, 33(3), 205-218.

McCarthy, M.M. (1993). Challenges to the Public School Curriculum: New Targets and Strategies. Phi Delta Kappan, 75(1), 58-60.

Schwarts, G., Cavener, L. (1994). Outcome Based Education and Curriculum Change: Advocacy, Practice and Critique. Journal of Curriculum and Supervision, 9(4), 326-338.

Spady, W. (1994). Outcome-Based Education: Critical Issues and Answer. American Association of School Administrators.

The Government of the Hong Kong Special Administration Region (2017).Qualification Framework < http://www.jpf.go.jp/j/project/japanese/survey/area/country/2016/hongkong.html > (2017 年 11 月 29 日)

The Government of the Hong Kong Special Administration Region (2017).Award Titles Scheme <https://www.hkqf.gov.hk/en/KeyFeatures/ats/index.html> (2017 年 11 月 29 日)

The Government of the Hong Kong Special Administration Region (2017).QF Levels <https://www.hkqf.gov.hk/en/KeyFeatures/levels/index.html> (2017 年 11 月 29 日) 